\title{
The Geneva Risk and Insurance Review 2009: In Quest of Behavioural Insurance
}

\author{
J. François Outreville \\ HEC Montréal, 3000 cote Sainte Catherine, Montreal, Quebec, Canada H3T 2A7. \\ E-mail: j-francois.outreville@hec.ca
}

The purpose of this article is to review and summarize the papers published in The Geneva Risk and Insurance Review in 2009. Asymmetric information, adverse selection and moral hazard are the keywords in several papers in this volume. These papers highlight how applied research in insurance could help understand the behaviour of policy-holders and have important implications for the insurance industry. This is an important issue in insurance and the papers summarized in this article raise some interesting potential empirical research questions and call for a behavioural research approach applied to insurance, a field that could be defined as behavioural insurance.

The Geneva Papers (2010) 35, 484-497. doi:10.1057/gpp.2010.14

Keywords: asymmetric information; behavioural economics; insurance

\section{Introduction}

During the past five years (vol. 30, 2005 to vol. 34, 2009) The Geneva Risk and Insurance Review (GRIR) has published 43 papers dealing with the theoretical foundations of insurance contracts and including only a few empirical papers. ${ }^{1}$ Among the most popular topics, the issue of adverse selection, asymmetric information and moral hazard has been examined in one out of five papers published. Explaining a behaviour that does not necessarily conform to standard economic models of choice and decision-making is a fundamental issue in insurance. ${ }^{2}$ Other subjects that have been addressed in several papers are questions related to risk aversion, optimal contracts, market equilibrium and the impact of the value at risk (VaR) constraint. Pension schemes and annuities is the business that has received most attention. By comparison, property-liability business has received relatively little attention in the review.

The purpose of this article is to review and summarise the papers published in the GRIR in 2009. This volume of the GRIR is particularly important, not only because it includes two empirical papers, ${ }^{3}$ but also two papers deal with property-liability business (commercial fire insurance and liability insurance). ${ }^{4}$ Asymmetric information,

\footnotetext{
${ }^{1}$ This corresponds to the date when the change of name from the Geneva Papers on Risk and Insurance Theory to The Geneva Risk and Insurance Review took place.

${ }^{2}$ Cutler and Zeckhauser (2004) discuss selected kinds of anomalies related to insurance.

${ }^{3}$ Wang et al. (2009) and Hammitt et al. (2009).

${ }^{4}$ Wang et al. (2009) and Bajtelsmit and Thistle (2009).
} 
adverse selection and moral hazard are again the keywords in several papers in this volume.

In all the papers dealing with moral hazard, the policy-holder has the capacity to take action that will affect the occurrence of a risk through self-protection. ${ }^{5}$ Another important topic to be considered is insurance fraud and the strategy of the insurer in dealing with this problem. Insurance fraud is a problem of hidden information but is also considered by many authors as a particular case of moral hazard. Although several papers on insurance fraud have used the usual setting of rationality and optimisation, ${ }^{6}$ the behaviour of policy-holders towards fraud, underlying this theoretical problem, could also be based on a principle of satisfaction rather than a principle of optimisation. ${ }^{7}$

A paper is investigating empirically the effects of health and life expectancy on financial risk tolerance. The individual's investment risk attitude shows several underlying factors that determine the level of risk tolerance. Other papers are looking the role of brokers in the distribution of reinsurance, and optimal insurance design under VaR constraints.

The following sections of this paper will present an overview of the major topics presented above and which are explored in seven papers published in GRIR 2009. The last section will summarise the EGRIE keynote address at the 2008 meeting in Toulouse. Brief remarks conclude the paper.

\section{Asymmetric information and adverse selection}

In economics and contract theory applied to insurance, most papers assume some form of asymmetric information. The insured is assumed to either have information that is relevant to the contract but that is unknown to the insurer (adverse selection) or to be able to perform some relevant action that is hidden to the insurer (moral hazard). Theoretical models predict that both adverse selection and moral hazard in insurance markets may generate inefficient outcomes.

Commonly, information asymmetries are studied in the context of a principal-agent relationship, where the principal cannot have full information regarding the work of the agent and must rely on proxy indicators. When the insurance buyer (the agent) makes his decision, he inevitably conveys some information to the insurer (the principal). If the buyer prefers not to buy full insurance coverage, it is interpreted by the insurer as a "signal" that he represents a lower risk than a buyer requesting full insurance coverage. Of course the signal may prove wrong and it may take time for the insurer to realize the erroneous classification of the risk. Such relationship normally involves some element of bargaining.

In GRIR 2009, the paper by Quiggin and Chambers ${ }^{8}$ examines the interaction between differential bargaining power and the efficiency of insurance contracts. This

\footnotetext{
${ }^{5}$ It is meaningful to mention that the most quoted paper in this volume is Ehrlich and Becker (1972).

${ }^{6}$ See for instance the survey by Picard (2000).

${ }^{7}$ This was pointed out long time ago by Simon (1955).

${ }^{8}$ Quiggin and Chambers (2009).
} 
paper derives results from the fact that policy-holders can exploit asymmetric information to offset the bargaining power of the insurer. It shows that in the absence of insurance, a risk-averse individual will engage in self-insurance and self-protection by choosing a situation that generates less risky returns, at the cost of lower mean returns than the maximum available. The existence of market insurance will affect his decision. The individual may choose to undertake, or not undertake, costly selfinsurance and self-protection to improve the ultimate outcome of bargaining. This is analysed by the authors in the context of a "hold-up problem", a situation where two parties may be able to work most efficiently by cooperating (a Pareto efficient solution), but refrain from doing so because of concerns that they may give the other party increased bargaining power. ${ }^{9}$

In their paper, the authors are considering the two extreme cases of a monopolistic market and a perfect competitive market with a zero-expected profit constraint for insurers. The agent anticipating the need to deal with an insurer with monopoly power will undertake costly self-protection to improve his bargaining situation. By doing so, he may invest in self-protection in excess of the optimal amount. In a competitive market, the insurer must offer the most appealing contract and the agent is better off as expected. However, in the case of asymmetric information, both the agent and the insurer are strictly worse off (incur a cost). The relative bargaining power of the parties will affect the outcome, that is, an increase in the agent's bargaining power increases the agent welfare and reduces the insurer's welfare and vice versa.

In the specific case of adverse selection, the traditional theoretical literature shows that if there is a market equilibrium, it has to be a separating one in which different types of risks are offered different types of contracts. High risk individuals would buy full insurance coverage and low risk individuals would buy only partial insurance coverage and this imply that insurance coverage and risk occurrence are positively correlated.

However, there are various reasons why a coverage-risk correlation may not be found in some markets or pools of insurance policies. ${ }^{10}$ Previous works in health

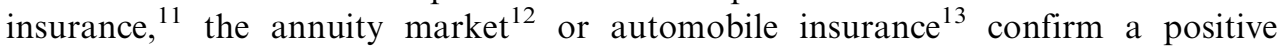
correlation, but the presence of a coverage-risk correlation can be explained either by moral hazard or adverse selection; thus, the existence of coverage-risk correlation is not sufficient to confirm the presence of adverse selection. ${ }^{14}$

On the contrary, various authors find evidence of a negative correlation in other insurance markets such as life insurance ${ }^{15}$ or the long-term care insurance. ${ }^{16}$ Several

\footnotetext{
${ }^{9}$ The hold-up problem has played an important role in modern contract theory and organisation theory (see Schmitz (2001) for a survey of the literature).

${ }^{10}$ Cohen and Siegelman (2010) review the literature on adverse selection in insurance markets.

${ }^{11}$ Cardon and Hendel (2001).

${ }^{12}$ Finkelstein and Poterba (2004).

${ }^{13}$ Chiappori and Salanié (2000) and Saito (2006).

${ }^{14}$ Chiappori and Salanié (2000) stress that the positive correlation between risk and insurance demand is fairly robust (in theory). It does not depend on the market structure (perfect competition or monopoly). However, the existence of such a correlation is only a necessary condition for adverse selection to be present, and the absence of such a correlation is therefore sufficient for rejecting adverse selection.

15 Cawley and Philipson (1999).

${ }^{16}$ Finkelstein and McGarry (2006).
} 
explanations have been proposed for this negative correlation, but one is particularly appealing. Assume that individuals have different risk aversions and that more riskaverse individuals are more likely both to try to reduce the hazard and to purchase insurance. ${ }^{17}$ This would suggest a negative correlation between insurance coverage and accident frequency.

De Meza and Webb ${ }^{18}$ find for credit card insurance that a lower proportion of credit cards are reported stolen among those that are insured than among the uninsured. They also provide an interesting explanation by suggesting that adverse selection be replaced by "advantageous selection". The same argument has been called propitious selection by Hemenway ${ }^{19}$ who also assumes that potential insurance buyers have different tastes for risk and that they are consistent in their taste for risk across physical and financial dimensions.

The theory of De Meza and Webb is able to predict the result of at least two hypotheses: a positive relationship between the investment in self-protection and the purchase of insurance, and a negative relationship between the investment in selfprotection and the occurrence of risk. As in the case of previous research on adverse selection, insurance offers a particular promising field for empirical test on these hypotheses.

The first paper in GRIR 2009 by Wang, Huang and Tzeng ${ }^{20}$ provides empirical evidence of the relationships that exist between insurance purchase, self-protection and risk occurrence by focusing on the commercial fire insurance market in Taiwan. Rather than using only data provided by insurance companies, they collected information regarding the purchase of insurance, self-protection through risk control equipment and activities and records of fire accident, directly by surveying a sample of business firms. ${ }^{21}$ Data was also collected on relevant variables that insurance companies do know and use in pricing commercial fire insurance.

The empirical analysis in their paper was based on two different models to take care of the interactivity among the three endogenous variables and the fact that dummy variables are used to measure both the dependent and independent variables. The purchase of commercial fire insurance and the occurrence of fire accidents are significantly negatively correlated, and there is a positive correlation between the purchase of insurance and self-protection. As anticipated, the findings support the view that commercial firms that purchase insurance also make efforts to engage in risk control activities either through the purchase of safety equipment or the implementation of procedures (both the quantity and the quality of self-protection are significant factors). Finally, the efforts of self-protection and the occurrence of accidents are negatively correlated. These results are in accordance with the theory of advantageous selection.

${ }^{17}$ In Chiappori and Salanié's (2000) terms, more risk-averse drivers tend to both buy more insurance and drive more cautiously.

${ }^{18}$ De Meza and Webb (2001).

${ }^{19}$ Hemenway (1990).

${ }^{20}$ Wang et al. (2009).

${ }^{21}$ The claims records of insurance companies underestimate the occurrence of accidents because the insured may not report accidents involving small amounts. 
The paper by Bajtelsmit and Thistle ${ }^{22}$ looking at the demand for negligence liability insurance is also related to adverse selection and self-protection, since individuals take actions to reduce the probability of loss. Under the particularity of the law in the U.S., if an individual takes appropriate action (care), there is no liability and no reason to purchase insurance. Therefore the demand for negligence liability insurance may be explained by ignorance about the risks, the cost of being ignorant or the cost of complying with the standard of care. From the offer point of view, the insurance company faces an adverse selection problem since it is not possible to verify whether individuals are informed or uninformed and whether informed agents are low or high risks.

Crocker and Doherty ${ }^{23}$ assume an individualised negligence rule and argue that potential injurers face a choice between becoming informed and taking appropriate action and remaining uninformed and purchasing coverage. When individuals learn about the risks they face, they may discover that they are high risks and must meet a high standard of care. Therefore, buying insurance allows uninformed individuals to hedge the potential risk. In their paper, Bajtelsmit and Thistle assume a uniform negligence rule to all individuals. They demonstrate an opposite situation where insurance is purchased by informed individuals whose private level of care is below the negligence standard and the cost of being negligent and purchasing insurance is less than the cost of complying with the standard of care.

This paper raises some interesting potential empirical research questions to better understand under what circumstances or conditions (the value of information) should the uninformed individuals become informed about the risks they face and decide to buy insurance. Decisions that are complicated because of misperception of the risks or poor information may lead to a behaviour that differs from the normal model of choice.

\section{Asymmetric information and insurance fraud}

Insurance fraud is a typical case of asymmetric information where the insurer cannot distinguish between the actions that a policy-holder might pursue only at costly auditing of contracts and claims. It could also be defined, depending of the timing of the fraud, as ex-ante moral hazard in case of a fraudulent behaviour before the contract is signed, or ex-post moral hazard, a fraudulent claim in which there is no loss or the loss is exaggerated (a build-up claim). ${ }^{24}$

According to a 1996 Conning \& Co. insurance fraud study, "Insurance Fraud: The Quiet Catastrophe", it is estimated that $\mathrm{P} / \mathrm{C}$ insurers detect about 20 per cent of their fraud, while life/disability insurers find about 10 per cent and health care insurers a mere 1 per cent. A June 2000 study by the Insurance Research Council in the U.S. revealed that 35 per cent of Americans surveyed said that it is all right to exaggerate

\footnotetext{
22 Bajtelsmit and Thistle (2009).

23 Crocker and Doherty (2000).

${ }^{24}$ Spence and Zeckhauser (1971) were the first to recognise the difference between moral hazard ex-ante and ex-post and this approach has been frequently used to study insurance fraud (Boyer, 2003) and welfare consequences (Chiappori, 2001).
} 
insurance claims under certain circumstances. The fundamental problem for insurers coping with both fraud and systemic abuse is therefore to devise a mechanism that efficiently detects claims but requires the acquisition of additional information at a cost. ${ }^{25}$

Within the last 10 years, there has been substantial research in many aspects of insurance fraud. In GRIR 2009, Krawczyk ${ }^{26}$ analyses an important theoretical aspect of moral hazard which is related to the behaviour of policy-holders towards fraud when there is a cost to the insurer to effectively commit to a strategy to audit a credible amount of contracts to control underwriting fraud or claim fraud.

The model described by the author is a three-stage process or a game where (1) the insurer designs a contract, (2) the agent (policy-holder) chooses an action (lawful or fraudulent) and (3) the insurer chooses to investigate (audit) or not. By assumption, (1) it is in the insurer's interest to audit if and only if the policy-holder plays fraudulently or it is in the policy-holder's interest to play fraudulently only if the insurer does not audit (there is a penalty for fraudulent action) and (2) the insurer strictly prefers the policy-holder to play lawfully and the policy-holder strictly prefers not to be audited.

The question is whether or not the repetition of this game (the strategy of the insurer), according to the analysis of repeated games, ${ }^{27}$ allows the insurer to effectively deter fraud while keeping the investigation cost within an acceptable level?

The story goes like this: if the insurer in this kind of principal-agent interaction can credibly demonstrate to the agents that he can maintain the same long-term strategy of auditing a sufficient level of claims (or contracts), then agents base their decisions on observable information from the past periods and play lawfully. This can be done when the insurer establishes an investigation unit to give a signal that efforts to deter fraud are continued at constant level.

If, on the other side, the insurer deviates from this strategy by deciding on a lower frequency of audit, and if the agents realise this, then they choose the fraudulent action. This is a typical study case for behavioural economics. Since the author shows that even partial disclosure of relevant information regarding auditing frequency can reduce fraud, experiments could be used to determine the level of information which would produce a switching behaviour from the individual.

Considering that fraudulent actions account for a significant amount of business, the analysis and the understanding of the behaviour of policy-holders is an important issue in insurance and a particular promising field for empirical works in behavioural economics.

\section{Health and life expectancy related to risk tolerance}

Understanding the effects on tolerance to financial risk is important for a wide range of investment decisions. Risk tolerance is the extent to which an investor is

\footnotetext{
25 Derrig (2002).

${ }^{26}$ Krawczyk (2009).

${ }^{27}$ Fudenberg et al. (1990).
} 
comfortable with the risk of losing money on an investment, or in other words, his or her ability to handle declines in the value of a portfolio. Over the last years the growing acceptance of life cycle investment products, such as target retirement mutual funds, has renewed interest in this topic.

Review of the literature in the area of the individual's investment risk attitude shows several underlying factors that determine the level of risk tolerance. Among the most important socioeconomic factors are gender, age and wealth. ${ }^{28}$ Younger people should be more tolerant of risks to income because of a time-diversification effect. For example, a 70-year-old retired individual will generally have a lower risk tolerance than a single 30 -year-old executive, who generally has a longer time frame to smooth consumption over time.

But there is also an additional effect. If the risk to income depends on the number of years left to live, younger people would face a greater risk to lifetime income. As a result, younger people may be less willing to accept a risk that affects income in every future year of their lives. The total effect of longevity on tolerance of income risk thus depends on two opposite effects: the time-diversification effect and the lifetime-income effect. As a result, when the individual smoothes consumption, the time-diversification and lifetime-income effects may cancel and there is no effect of longevity on tolerance of income-risk. In other words, academics can prove or disprove time diversification depending on the hypothesis concerning the risk aversion behaviour of individuals. ${ }^{29}$ Thus, the time-diversification controversy is an empirical issue.

Using a standard life-cycle model, Hammitt, Haninger and Treich in GRIR 2009 are providing empirical results on this issue by describing how life expectancy but also health is affecting risk tolerance. ${ }^{30}$ Health has received very little attention in economic models of consumption and financial risk taking. However, it may affect the marginal utility of consumption (consumption patterns) and the shape of utility functions. Health also influences life expectancy and thus affects the expected values of future consumption and future earnings. Third, health may affect productivity and flexibility to adapt and thus affect future income streams.

The effect of health on medical expenditures may be negligible if the individual has full health insurance. Similarly, the effect of health on future income may be ignored if the individual is assumed to have a constant income over his lifetime through social or private disability insurance coverage. Therefore, this paper focuses on the effect of health on the marginal utility of consumption. Health may affect risk tolerance when individuals do not perfectly smooth consumption. If the individual is able to smooth consumption over his remaining lifetime, then health will have no effect on the willingness to accept a risk on lifetime income.

\footnotetext{
${ }^{28}$ Al-Ajmi (2008).

${ }^{29}$ If consumption is exactly at the subsistence level, the household may not be willing to bear any risk. If this is the case, then the relative risk aversion (RRA) coefficient must be a decreasing function of wealth. However, some existing tests in the empirical literature are derived using preferences that exhibit either increasing or constant RRA even when they are applied to data containing low-income households. Therefore, the use of a Hyperbolic Absolute Risk Aversion (HARA) utility, which implies increasing, constant and decreasing RRA as special cases, must be a preferred assumption.

${ }^{30}$ Hammitt et al. (2009).
} 
Hammitt, Haninger and Treich conducted a survey of adults in the U.S. Questions are designed for respondents to measure their current health. Longevity is based on the age of the respondent. To measure preferences for gamble on lifetime income, questions explore the behaviour of people when faced with a choice between a safe situation and a risky situation (an approach similar to the usual design of questionnaires in behavioural economics). Without assuming any particular form of the utility function, respondents are classified into four groups by increasing level of relative risk tolerance.

Examining the distribution of respondents across the four risk-tolerance groups, they find that risk tolerance decreases with age. Life expectancy being negatively related to age, the result is a significant positive correlation between risk-tolerance and life expectancy. Similarly, they find that risk-tolerance increases with people reporting "better" health, whichever measure is used to assess the health status of the respondents.

Risk tolerance is modelled as a function of health, life expectancy and other respondent's characteristics. Empirical results imply that health and longevity are significantly positively related to risk-tolerance, a deviation from the theoretical analysis. This has important implications not only for further research on the relationship between health, ageing and risk taking, but also on research on the potential role and availability of health insurance and life insurance products in the investment decision process.

\section{The role of reinsurance brokers}

A quick look at the main reinsurance groups over the past 10 years shows a significant change in market participants. The consolidation of the reinsurance market in the 1990s, both reinsurance groups and brokers groups, has significantly increased the market share of the largest companies. Three countries (Germany, U.S. and Switzerland) dominate the reinsurance business worldwide with more than 60 per cent of total reinsurance premiums but recent years have seen the emergence of Bermuda (a brokers' driven market) as a major reinsurance centre. ${ }^{31}$

Motivated by the increasing role of brokers and measures taken by the European Commission to regulate some of the activities of insurance and reinsurance intermediaries, Sonnenholzner, Friese and Graf v.d., in this GRIR volume, analyse reinsurance brokers' advice quality in relation to the price they charge for their services. ${ }^{32}$ The literature on insurance distribution mainly focuses on the coexistence of insurance brokers and exclusive agents. The existence of brokers, even though they are apparently more expensive, is explained either by agency costs and conflicts between insurers and their agents, or by the value-adding services the broker provides to his clients.

The value-added service could be related to ex-ante situations (selection of the best insurance contract) or ex-post situations (selection of the best claims settlement process). A value-added service would be expected in commercial lines where the

\footnotetext{
31 Outreville (2003).

${ }^{32}$ Sonnenholzner et al. (2009).
} 
selection of the best insurance contract is more difficult. In personal lines (automobile and homeowners) the client would prefer an exclusive agent or a direct writing company. Another explanation would be that high-risk clients choose a broker whereas low-risk clients prefer to buy directly; ${ }^{33}$ a separating equilibrium similar to the case we have seen before for asymmetric information.

The paper by Sonnenholzner et al. is relevant in the sense that in the reinsurance business, a value-added service is expected from a broker. Ceding companies could buy directly from a reinsurer or consult a reinsurance broker and the quality of advice is perfectly observable. The model described in this paper considers the case of one broker either in a monopolistic situation or facing the competition from potential new entrants.

A monopoly reinsurance broker will always offer an advice quality that is lower than the social optimum and at a price that is higher than the social optimum. This result is obviously similar to the bargaining power situation examined by Quiggin and Chambers in this GRIR volume. ${ }^{34}$ A higher welfare level can only be obtained by regulation of both the reinsurance broker's price and quality of advice.

When the reinsurance broker faces the threat of market entry by competitors, quality of advice is improved and at a lower price. The equilibrium price-advice quality combination offered will depend on the flexibility of price or advice quality (taking into account the cost function of investing in advice quality) or both. However, the optimal welfare level is never achieved and the question raised in the paper is why and how the reinsurance broker should be regulated. The findings support the role of regulation in imposing a minimum standard for advice quality from reinsurance brokers.

\section{Optimal insurance design under VaR constraints}

VaR has emerged as the standard tool for measuring financial risks and the past decade has witnessed a surge in the effort financial market participants devote to risk management. ${ }^{35} \mathrm{VaR}$ measures the worst expected loss under normal market conditions over a specific time interval at a given confidence level. In other words, VaR answers the question: How much can I lose with $x$ per cent probability over a preset horizon? (J.P. Morgan, RiskMetrics-Technical Document).

In previous volumes of GRIR, papers have looked at the insured's VaR constraint into the optimal insurance decision. ${ }^{36}$ The question is the following: what is the impact of the insurer's risk constraint on the insurer's terminal wealth and on the insured's terminal wealth?

\footnotetext{
${ }^{33}$ Venezia et al. (1999).

${ }^{34}$ Quiggin and Chambers (2009).

35 The financial turbulences in emerging markets, starting in Mexico in 1995, continuing in Asia in 1997, and spreading to Russia and Latin America in 1998, have extended the interest in risk management but the "safety-first" principle is as old as Condorcet. For a comprehensive history of the Value at Risk concept, see Pradier (2005).

${ }^{36}$ Wang et al. (2005) and Huang (2006).
} 
The purpose of the paper by Zhou and $\mathrm{Wu}^{37}$ is to solve the optimisation problem, following an approach used in the literature on optimal indemnity schedules. ${ }^{38}$ Insured could get higher expected utility if insurance contracts would allow payments from the insured to the insurer at some losses. They demonstrate that when the insurer's VaR constraint is binding, there is a non-linear solution and the insured's optimal expected utility will increase as the insurer becomes more risk tolerant. The insurer will suffer larger losses than optimal insurance without insurer's risk constraint. The mathematical explanation can be found in the paper and appendices contain detailed proofs. The paper also provides a simple example to illustrate the calculation process.

\section{The 2008 Geneva risk economics lecture}

This paper is based on the Geneva Risk Economics Lecture delivered in Toulouse, France, to the European Group of Risk and Insurance Economists in September $2008 .^{39}$ It examines the problem of portfolio allocation across different asset classes such as stocks, nominal government bonds, inflation-indexed government bonds and money market instruments.

In previous papers, ${ }^{40}$ Campbell shows empirical evidence of asset prices being mean reverting over the past 100 years and argue therefore that risks can appear different to long-term investors than to short-term investors. These results have significant importance for the issue of risk tolerance and the time-diversification effect discussed in a previous section. Conventional analysis assumes that broad asset classes have stable risks (the term structure is constant over time), which can be measured by looking at the covariances of asset classes over long periods of time. However, from data evidence in recent past decades, it has become clear that this assumption is not sustainable.

In this paper Campbell examines the contribution of nominal government bonds in a portfolio. ${ }^{41}$ When such instruments are included, as it is almost always the case, the assumption of constant risks is dangerously misleading since the covariance between nominal bonds and stocks has varied considerably over recent decades, even switching from positive to negative.

Inflation plays a relatively important role for investors when nominal government bonds are considered (used as instruments) in a portfolio. Nominal bond prices fall when expected inflation increases and movements in expected inflation are associated, positively correlated with stock returns during the 2000s. Macroeconomic models can be used to understand why the covariance of inflation with the stock market might change over time.

The author suggests a model of nominal bond pricing developed with other co-authors and presenting three important properties: ${ }^{42}$ (1) must allow for changes

\footnotetext{
${ }^{37}$ Zhou and $\mathrm{Wu}(2009)$.

${ }^{38}$ See Breuer (2006) for a more recent paper.

${ }^{39}$ Campbell (2009).

${ }^{40}$ Campbell and Viceira $(2002,2005)$.

${ }^{41}$ Campbell (2009).

${ }^{42}$ Campbell et al. (2009).
} 
over time in the risks of nominal bonds; (2) must allow the covariance between bond and stocks returns to switch sign; and (3) changing risks of nominal bonds should be linked to the behaviour of inflation. By looking over different periods of time from 1953 to 2002 he demonstrates the changing role of bonds for short-term investors and long-term investors and shows how investors should respond to changes over time in the covariance between nominal bonds and stocks.

For short-term investors, nominal returns have almost a guaranteed return since short-term inflation is highly predictable. In addition, mean returns and variance are relatively stable over a short period of time and the traditional mean-variance portfolio analysis can be used to evaluate the role of nominal bonds, that is, the weight of bonds will depend on the mean returns of bonds and stocks, their variances, and the covariance between them. With the negative correlation with stocks in the $1950 \mathrm{~s}$, mid-1960s and 2000s (especially during the downturn of 2007-2008), bonds play a dominant role in the portfolio.

For long-term investors, nominal bonds play an even more important role. If inflation-indexed bonds are not available, long-term investors must combine nominal bonds with other assets to minimise their risk. With the phenomenon of changing covariance discussed in this paper, nominal government bonds become the dominant assets in the portfolio but inflationary expectations may change asset allocation and investors should be aware of the changing covariances among the different assets classes.

\section{Discussion}

Among the papers published in this volume of the GRIR, some provide direct insights to the insurance industry by demonstrating, for example, the positive relationship between the purchase of insurance and the decision to engage in risk control activities. The issue of adverse selection, asymmetric information and moral hazard has been examined in several papers and is of particular relevance for insurers and the proper functioning of insurance markets. The proper disclosure of information is also relevant in many aspects of attitude toward risk and insurance purchase. In the case of insurance fraud, the concern of the insurer, and its strategy in dealing with this problem, is to convey credible information regarding its auditing practices. In the demand for liability insurance, informed individuals, who purchase insurance, are always better off. In the reinsurance business, a value-added advice or information is expected from a broker.

Considering the importance of asymmetric information, adverse selection and moral hazard for insurance business and markets, these papers raise also some interesting potential empirical research questions to better understand how the misperception of the risks or poor information may lead to a behaviour that differs from the expected outcome. All these perspectives on decision-making under uncertainty or decisionmaking under ignorance remain an important issue. ${ }^{43}$

\footnotetext{
${ }^{43}$ See Thomas (2007).
} 
Determinants of risk attitudes of individuals are of great interest in a growing area of finance known as behavioural finance and which emerged from the field of behavioural economics. Behavioural finance encompasses research that drops the traditional assumptions of expected utility maximisation and focuses on the individual attributes, psychological or otherwise, that shape common financial and investment practices. ${ }^{44,45}$

When risk and uncertainty or incomplete information about an alternative is introduced, people or organisations may behave somewhat different from rationality. ${ }^{46}$ It has been argued that insurance offers a particularly promising field for empirical work on contracts. ${ }^{47}$ The papers summarised in this article raise some interesting potential empirical research questions and call for a behavioural research approach applied to insurance (a field that could be defined as behavioural insurance), to better understand under what circumstances or conditions (the value of information) should the uninformed individuals become informed about the risks they face, or under which conditions people's decisions to pay for insurance may lead to suboptimal outcomes and market anomalies.

Two potential topics examined in this volume of the GRIR are of particular relevance for this approach. Insurance fraud is a typical case of asymmetric information where the insurer cannot distinguish between the actions that a policy-holder might pursue within a specified context. Risk tolerance is a function of health, life expectancy and other respondent's characteristics which has important implications not only for investment decisions matters but also on the potential role and availability of insurance products in the investment decision process. In both cases it is important to understand how individuals behave individually or collectively.

\section{Conclusion}

This article has summarised the papers published in the GRIR in 2009 (volume 34). The Geneva Association, through publications like the GRIR, serves as a catalyst for progress in the understanding of risk and insurance matters. Asymmetric information, adverse selection and moral hazard are the keywords in several papers. These papers highlight how applied research in insurance could help understand the behaviour of policy-holders and have important implications for the insurance industry.

The analysis and the understanding of the behaviour of policy-holders is an important issue in insurance and a particularly promising field for empirical works in behavioural economics. Most consequences of the behaviour of the individual facing uncertainty are applicable not only to insurance, but also to other sectors of the

\footnotetext{
44 Ritter (2003).

45 The behaviour of investors is not always rational and Barberis and Thaler (2003) consider that behavioural finance assumes people are "normal" (rather than utility maximisers).

46 The term "bounded rationality" is used to designate rational choice that takes into account the cognitive limitations of the decision-maker, limitations of both knowledge and computational capacity.

${ }^{47}$ See Chiappori and Salanié (2003) for a recent survey of papers that have recently been devoted to empirical application of the theory.
} 
financial services market. The field of behavioural insurance will certainly become a growing academic area in the future volumes of GRIR.

\section{References}

Al-Ajmi, J.Y. (2008) 'Risk tolerance of individual investors in an emerging market', International Research Journal of Finance and Economics 17(1): 15-26.

Bajtelsmit, V. and Thistle, P. (2009) 'Negligence, ignorance and the demand for liability insurance', The Geneva Risk and Insurance Review 34(2): 105-116.

Barberis, N. and Thaler, R. (2003) 'A survey of behavioral finance', in G.M. Constantinides, M. Harris and R. Stulz (eds.) Handbook of the Economics of Finance, Amsterdam: Elsevier Science B.V., pp. 1052-1114.

Boyer, M. (2003) 'Contracting under ex-post moral hazard and non-commitment', Review of Economic Design 8(1): 1-38.

Breuer, M. (2006) 'Optimal insurance contracts without the non-negativity constraint on indemnities: Revisited', The Geneva Risk and Insurance Review 31(1): 5-9.

Campbell, J.Y. (2009) 'The changing role of nominal government bonds in asset allocation', The Geneva Risk and Insurance Review 34(2): 89-104.

Campbell, J.Y. and Viceira, L.M. (2002) Strategic Asset Allocation: Portfolio Choice for Long-Term Investors, New York: Oxford University Press.

Campbell, J.Y. and Viceira, L.M. (2005) 'The term structure of the risk-return trade-off', Financial Analysts Journal 61(1): $34-44$.

Campbell, J.Y., Sunderam, A. and Viceira, L.M. (2009) Inflation bets or deflation hedges? The changing risks of nominal bonds, NBER Working Paper $\mathrm{N}^{\mathrm{o}} .14701$.

Cardon, J.H. and Hendel, I. (2001) 'Asymmetric information in health insurance: Evidence from the national medical expenditure survey', Rand Journal of Economics 32(3): 408-427.

Cawley, J. and Philipson, T. (1999) 'An empirical examination of information barriers to trade in insurance', American Economic Review 89(4): 827-846.

Chiappori, P.A. (2001) 'Econometric models of insurance under asymmetric information', in G. Dionne (ed) Handbook of Insurance, Boston: Kluwer Academic Publishers.

Chiappori, P.A. and Salanié, B. (2000) 'Testing for asymmetric information in insurance markets', Journal of Political Economy 108(1): 56-78.

Chiappori, P.A. and Salanié, B. (2003) 'Testing contract theory: A survey of some recent work', Advances in Economics and Econometrics 1(1): 115-149.

Cohen, A. and Siegelman, P. (2010) 'Testing for adverse selection in insurance markets', Journal of Risk and Insurance 77(1): 39-84.

Crocker, K. and Doherty, N. (2000) 'Why people buy liability insurance under the rule of simple negligence', in M.R. Baye (ed) Industrial Organization, Amsterdam: Elsevier Science.

Cutler, D. and Zeckhauser, R. (2004) Extending the theory to meet the practice of insurance, BrookingsWharton Papers on Financial Services, The Brookings Institute, Washington, DC.

De Meza, D. and Webb, D.C. (2001) 'Advantageous selection in insurance markets', Rand Journal of Economics 32(2): 249-262.

Derrig, R.A. (2002) 'Insurance fraud', Journal of Risk and Insurance 69(3): 271-287.

Ehrlich, I. and Becker, G. (1972) 'Market insurance, self-insurance and self-protection', Journal of Political Economy 80(4): 623-648.

Finkelstein, A. and McGarry, K. (2006) 'Multiple dimensions of private information: Evidence from the long-term care insurance market', American Economic Review 96(4): 938-958.

Finkelstein, A. and Poterba, J. (2004) 'Adverse selection in insurance markets: Policyholder evidence from the U.K. annuity market', Journal of Political Economy 112(1): 183-208.

Fudenberg, D., Kreps, D.M. and Maskin, E.S. (1990) 'Repeated games with long-run and short-run players', Review of Economic Studies 57(4): 555-573.

Hammitt, J.K., Haninger, K. and Treich, N. (2009) 'Effects of health and longevity on financial risk tolerance', The Geneva Risk and Insurance Review 34(2): 117-139.

Hemenway, D. (1990) 'Propitious selection', Quarterly Journal of Economics 105(4): 1063-1069. 
Huang, H.H. (2006) 'Optimal insurance contract under a value-at-risk constraint', The Geneva Risk and Insurance Review 31(2): 91-110.

Krawczyk, M. (2009) 'The role of repetition and observability in deterring insurance fraud', The Geneva Risk and Insurance Review 34(1): 74-87.

Outreville, J.F. (2003) 'Le marché mondial de la réassurance', Assurances et Gestion des Risques 71: 455-460.

Picard, P. (2000) 'Economic analysis of insurance fraud', in G. Dionne (ed) Handbook of Insurance, Boston: Kluwer Academic Publishers.

Pradier, P.C. (2005) Value at risk since 1784: A comprehensive history, Working Paper, from www .univ-orleans.fr/deg/GDRecomofi/Activ/pradier_strasbg05.pdf.

Quiggin, J. and Chambers, R.G. (2009) 'Bargaining power and efficiency in insurance contracts', The Geneva Risk and Insurance Review 34(1): 47-73.

Ritter, J.R. (2003) 'Behavioral finance', Pacific-Basin Finance Journal 11(4): 429-437.

Saito, K. (2006) 'Testing for asymmetric information in the automobile insurance market under rate regulation', Journal of Risk and Insurance 73(2): 335-356.

Schmitz, P.W. (2001) 'The hold-up problem and incomplete contracts: A survey of recent topics in contract theory', Bulletin of Economic Research 53(1): 1-17.

Simon, H.A. (1955) 'A behavioral model of rational choice', Quarterly Journal of Economics 69(1): 99-118.

Sonnenholzner, M., Friese, S. and Graf v.d. Schulenburg, J.M. (2009) 'Reinsurance brokers and advice quality: Is there a need for regulation?' The Geneva Risk and Insurance Review 34(1): 20-46.

Spence, M. and Zeckhauser, R. (1971) 'Insurance, information and individual action', American Economic Review 61(2): 380-387.

Thomas, R.G. (2007) 'Some novel perspectives on risk classification', The Geneva Papers on Risk and Insurance-Issues and Practice 32(1): 105-132.

Venezia, I., Galai, D. and Shapiro, Z. (1999) 'Exclusive vs. independent agents: A separating equilibrium approach', Journal of Economics Behavior and Organization 40(4): 443-456.

Wang, K.C., Huang, R.J. and Tzeng, L.Y. (2009) 'Empirical evidence for advantageous selection in the commercial fire insurance market', The Geneva Risk and Insurance Review 34(1): 1-19.

Wang, C.P., Shyu, D. and Huang, H.H. (2005) 'Optimal insurance design under a value-at-risk framework', The Geneva Risk and Insurance Review 30(2): 161-179.

Zhou, C. and Wu, C. (2009) 'Optimal insurance under the insurer's VaR constraint', The Geneva Risk and Insurance Review 34(2): 140-154.

\section{About the Author}

J. François Outreville is Adjunct Professor of risk management and insurance in the Finance department at HEC Montreal in Canada. He was previously an economist at the United Conference on Trade and Development (UNCTAD), Geneva, in the Division on Investment, Technology and Enterprises. 